\author{
W. John Gould \\ Scripps Institution of Oceanography • La Jolla, California USA
}

On July 31, 2003, an Earth Observations Summit was held in Washington D.C. that, if its proponents are correct, will herald a concerted effort to provide the monitoring of our global environment that appears to many to be essential in addressing how and why our earth is changing. The oceans, covering $71 \%$ of the earth's surface and containing $96 \%$ of its water, are a vital element that needs to be adequately observed so that it can be satisfactorily represented in climate simulations. We are indeed fortunate that most of the systems and infrastructure elements that are needed to observe the oceans are already in place. It was not always so and our present relatively strong position is due to efforts by the science community over the past 20 years. Twenty years is a rather short period, certainly in terms of the 125 year lifetime of scientific ocean exploration if we mark its start with the 1873-1876 voyage of HMS Challenger. Yet these two decades have seen a revolution in our ability to observe the oceans and understand how they "work". This revolution (from a physical standpoint at least) was driven by the Tropical Ocean Global Atmosphere study (TOGA) and the World Ocean Circulation Experiment (WOCE). Both were part of the wider World Climate Research Program (WCRP).

\section{A Historical Perspective}

First let's look at what was happening about 20 years ago. In 1981 the space Shuttle Columbia made its first flight, CDs were introduced by the recording industry, the first IBM PC was marketed in 1981 and in 1982 the weather around the globe was disrupted by what we now know was a very powerful El Niño event (Canby, 1984).

Peru and Ecuador had their heaviest ever recorded rains (northern Peru receiving about 340 times the average figure) and suffered serious flooding, as did parts of the western USA. Eastern Australia endured one of its worst ever droughts, resulting in a \$2000 million loss in agricultural production, as well as bushfires and dust storms. Indonesia also had dry conditions, and the monsoon rains failed as far away as India. The fisheries industry off the Pacific coast of South America lost about $\$ 290$ million as catches declined.
The inhabitants of Pacific islands experienced anomalous weather conditions and monitoring of island and coastal temperatures and sea level across the Pacific and on the west coast of South America showed a warming trend progressing eastwards. These sparse observations gave no hint that this might be the start of what was soon to be considered the most severe El Niño during the modern era. That was not recognized until it had almost reached its peak in December, 1982 (Cane, 1983).

Satellite temperature sensors were available but the processing of the data was complicated by the aerosol impacts of the El Chichon eruption in March and April, 1982 and had been done in such a way that the anomalous ocean temperatures had been rejected as erroneous since they lay outside the projected error limits. What is more, the observations that were available did not fit what was then seen as the classical development pattern of an El Niño event, with an initial buildup of warm water in the western Pacific.

A purpose-built ocean observing satellite (SeaSatA) had been launched (and failed after 100 days) in 1978 but had, in its short life, demonstrated the potential for useful radar altimetry and for scatterometers to measure the surface wind field (Bernstein, 1982; Kirwan et al., 1983). Both of these might have helped to detect the 1982/3 ENSO event.

SeaSat had a profound effect in many areas of ocean science. Its altimeter that it carried showed that it was feasible to monitor the major current systems of the world ocean. The $\sim 1 \mathrm{~m}$ sea level change across the Gulf Stream was documented as was (through the study of repeated passes) the transient nature of ocean eddies. For the first time, synoptic studies of the oceans at global scale were possible.

Returning to the 1982/3 timeframe, analysis was under way (Roemmich and Wunsch, 1985) of two transAtlantic hydrographic sections taken in mid-1981 at $36^{\circ}$ and $24.5^{\circ} \mathrm{N}$ in the Atlantic Ocean. These were among the very small number of transocean sections that had been occupied since the International Geophysical Year in 1957-8. Such basin-scale hydrography had almost ceased. Exploration of the mesoscale in the western $\mathrm{N}$ Atlantic was a growth industry stimulated by the 

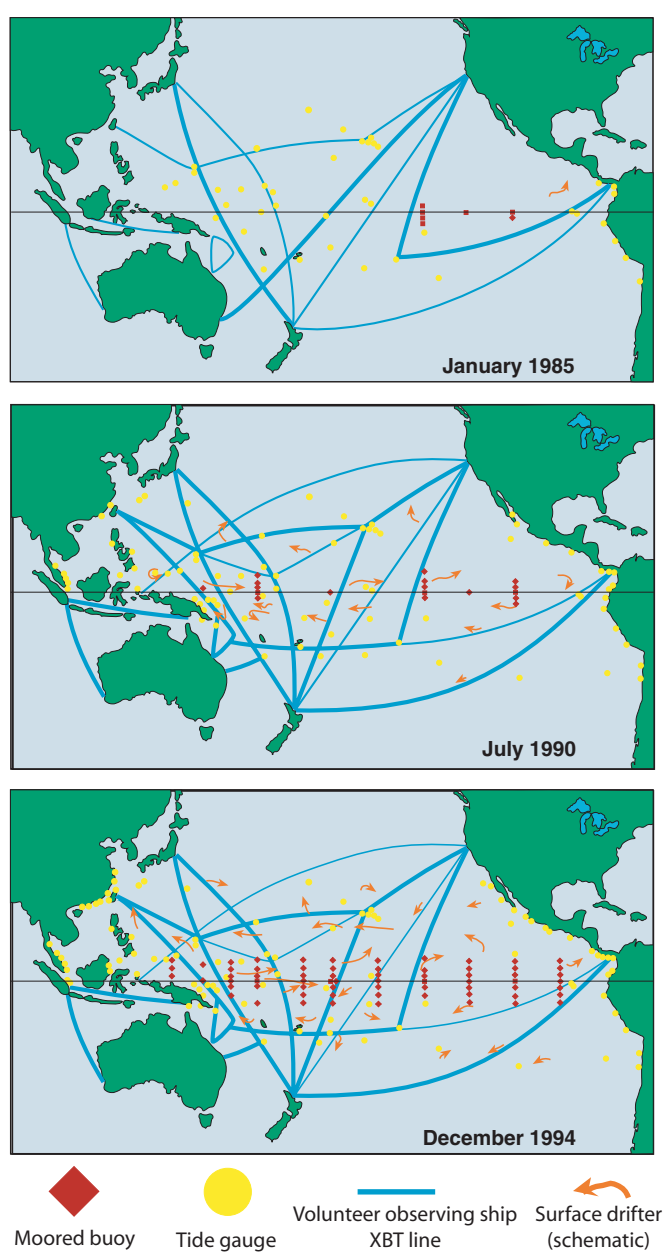

Figure 1. The evolution of the Pacific Ocean ENSO observing system. Figure courtesy of NOAA/PMEL.

fascinating "spaghetti diagrams" drawn by the acoustically tracked SOFAR floats. The floats were limited to that region by the need for acoustic tracking. At the ocean surface, rather cumbersome satellite-tracked drifters of the FGGE design were deployed globally (if sparsely)—some 800 buoys between 1978 and 1994! The estimates of surface currents they produced were difficult to interpret as a result of the significant windage contamination. So, global scale in situ observations were sparse and a high resolution global ocean circulation models then had a grid resolution of $250 \mathrm{~km}\left(2.5^{\circ}\right)$ !

\section{The Revolution}

So what drove the changes in our ability to observe the oceans in the past 20 years?

The magnitude, impact and degree of unpreparedness for the 1982/3 El Niño was a wake-up call for scientists to establish an observing and data delivery system that would, together with new satellite sensors, enable the first indications of any future event to be quickly recognized. In parallel with this there was a recognized need to improve the, then, rather rudimentary, predictive ocean modeling capabilities. The centerpiece of the observing system was to be the Tropical Atmosphere Ocean (TAO) moored buoy array making meteorological, surface and subsurface ocean observations in a low latitude band across the Pacific. The network of island observing sites was expanded and improved and a web of XBT lines measuring upper ocean temperatures from merchant ships was established and expanded. While the major motivator for the TAO array lay in the USA, and particularly at the National Oceanic and Atmospheric Administration's (NOAA's) Pacific Marine Environmental Laboratory (PMEL) where the late Dr. Stan Hayes was a constant source of energy, the overall international effort to observe and model El Niño-Southern Oscillation (ENSO) events came under the auspices of the WCRP's TOGA (Anderson et al., 1998) program established in 1985 with aims:

- To gain a description of the tropical oceans and the global atmosphere as a time-dependent system, in order to determine the extent to which this system is predictable on timescales of months to years, and to understand the mechanisms and processes underlying that predictability.

- To study the feasibility of modeling the coupled ocean-atmosphere system for the purpose of predicting its variations on timescales of months to years.

- To provide scientific background for designing an observing and data transmission system for operational prediction if this capability is demonstrated by the coupled ocean-atmosphere system.

The first prototype ATLAS (Autonomous Temperature Line Acquisition System) buoy with a design lifetime of one year was deployed in early 1984 and a skeleton array on $110^{\circ} \mathrm{W}$ was in place by later that year. This slowly grew until the full 70 buoy (TAO) array was completed in December 1994 (ironically, just as TOGA ended). (Figure 1)

Now the tropical arrays are expanding to populate other oceans. Partnership between the USA, Japan and France in maintaining the TAO/Triton (Triangle Trans Ocean Buoy Network) array means that Japanese buoys are now in the eastern Indian Ocean and the western Pacific. An interest in understanding the modes of variability of the tropical Atlantic led to the establishment of PIRATA (Pilot Research Array in the Tropical Atlantic) with a small sparse array of TAO-like moorings maintained by the joint efforts of USA, France and Brazil. The full Indian Ocean array has yet to be funded and installed.

Perhaps the most striking outcome of these efforts has been the real-time availability of the surface and subsurface data sets of tropical ocean variability. A visit to the PMEL TAO/Triton web site (http:/ / www.pmel. 


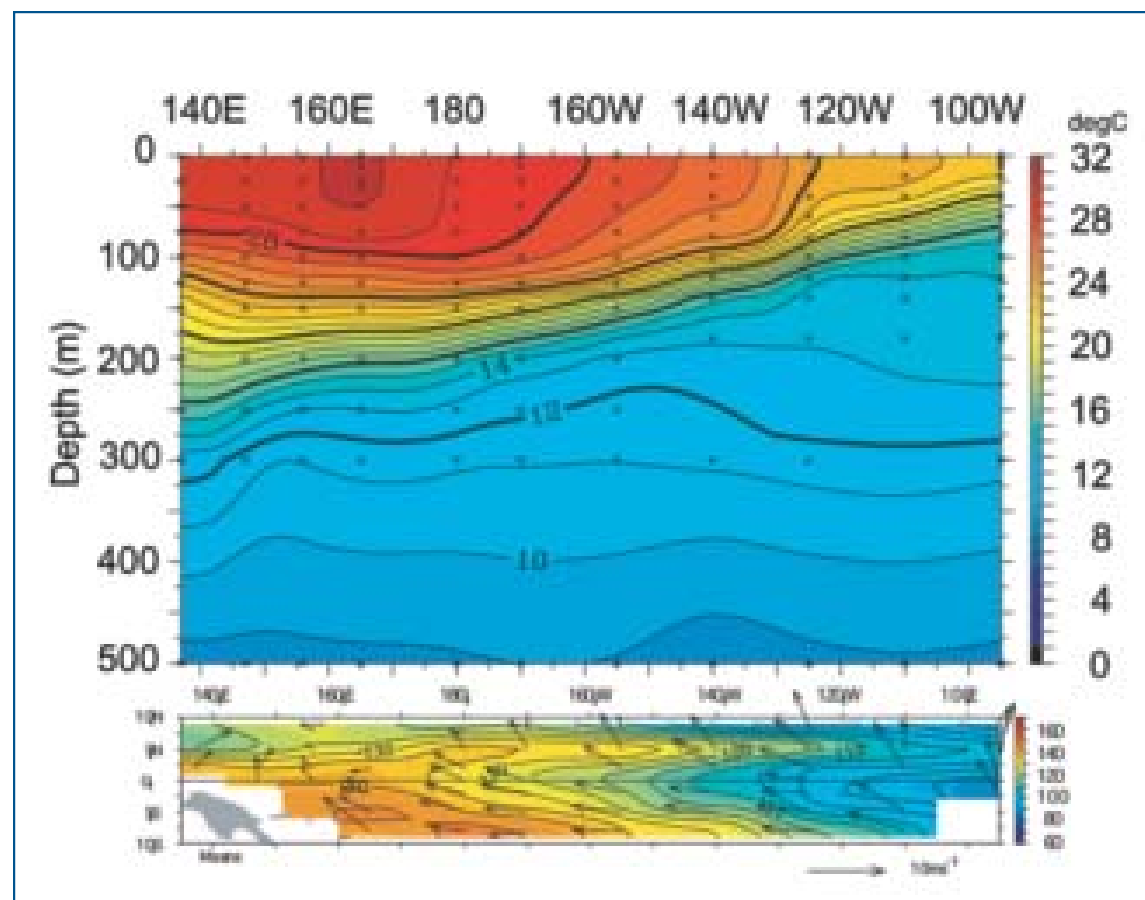

Figure 2. Conditions in the equatorial Pacific Ocean for a 5 day period ending September 9, 2003: a) Mean temperature $2^{\circ} \mathrm{N}$ to $2^{\circ} \mathrm{S}$; $\boldsymbol{b}$ ) Dynamic height $\mathrm{cm}$ $(0-500 m)$ plus wind vectors. Figure courtesy of NOAA/PMEL.

models for use in climate research, but within the context of collecting global in situ and satellite data sets to validate and initialize these models. (Papers covering all topics relating to WOCE and a comprehensive bibliography can be found in Siedler et al., 2001).

What was being undertaken was, just as TOGA had been, groundbreaking. There were many strands to the observational network that WOCE planners envisaged and each required substantial changes in the way things were done. These are summarized in Table 1.

In the early 1990s the required satellites (ERS-1, launched in 1991 and Topex-Poseidon, 1992 and still operating today) were launched. In general the in situ observing technologies were not new, but techniques that were experimental in the mid 1980s had to be developed to the point at which they could be implemented in many laboratories worldwide and deliver data of uniformly high quality.

Arguably the observational tech-

noaa.gov/tao/) enables one to access "Today's Pacific Conditions" and to see an animation of how the thermocline structure across the entire equatorial Pacific has altered each month over the past 5 years (Figure 2)

We are now in a situation where these comprehensive observations raise our expectations of ability to predict the onset and progress of future ENSO events. We have come a long way down the path of the second objective of TOGA.

Returning to the truly global perspective, interest in establishing further satellite altimetry missions developed very quickly after SeaSat's demise. In parallel, both the WCRP and the Intergovernmental Oceanographic Commission (IOC)-sponsored Committee on Climate Change and the Oceans (CCCO) turned their attention to designing a program that would address the oceans' role in the earth's climate on timescales longer than one year. The roots of this interest probably lay in a meeting on a Pilot Ocean Monitoring Study (POMS) in Miami in November 1979 at which Carl Wunsch made a strong case for a global ocean circulation experiment that would combine both satellite and in situ observations.

By 1984 these ideas, nurtured by an increasing number of far-sighted individuals led to the publication in 1986 of a science plan, and in 1988 an implementation plan, for the World Ocean Circulation Experiment (WOCE). The underlying motivation for WOCE was the development of improved ocean nique that required the greatest degree of innovation was that needed to deliver subsurface velocity fields on a global scale. These would provide a velocity reference level that could be combined with hydrographic ( $\mathrm{T}$ and $\mathrm{S}$ ) observations and with drifter-derived velocities at the sea surface.

Neutrally buoyant floats had developed from the ship-tracked, short range versions first deployed as prototypes by John Swallow in 1955 (Crease, 1997). By the 1980s these SOFAR floats had multi-year duration but were tracked acoustically at ranges of up to $1000 \mathrm{~km}$ and were thus dependent on the existence of a tracking network. The problem of extension to global scales was solved by the development of the Autonomous Lagrangian Circulation Explorer (ALACE) described by Davis et al. (1992). Though the concept of, and funding for the development of a global float system started in the mid 1980s, the first prototype in the form that was ultimately used did not enter the water until 1988 and the first pilot deployment was made in the Drake Passage in 1990. Over 1200 of these globally trackable floats were deployed during the WOCE observational phase between 1990 and 1997 as well as a further 900 acoustically tracked floats. This represented a virtually full realization of the ambitious plan called for by WOCE even before the first prototype had entered the water-a truly amazing effort by all involved. For the first time, the subsurface velocity field could be measured directly across entire ocean basins. 


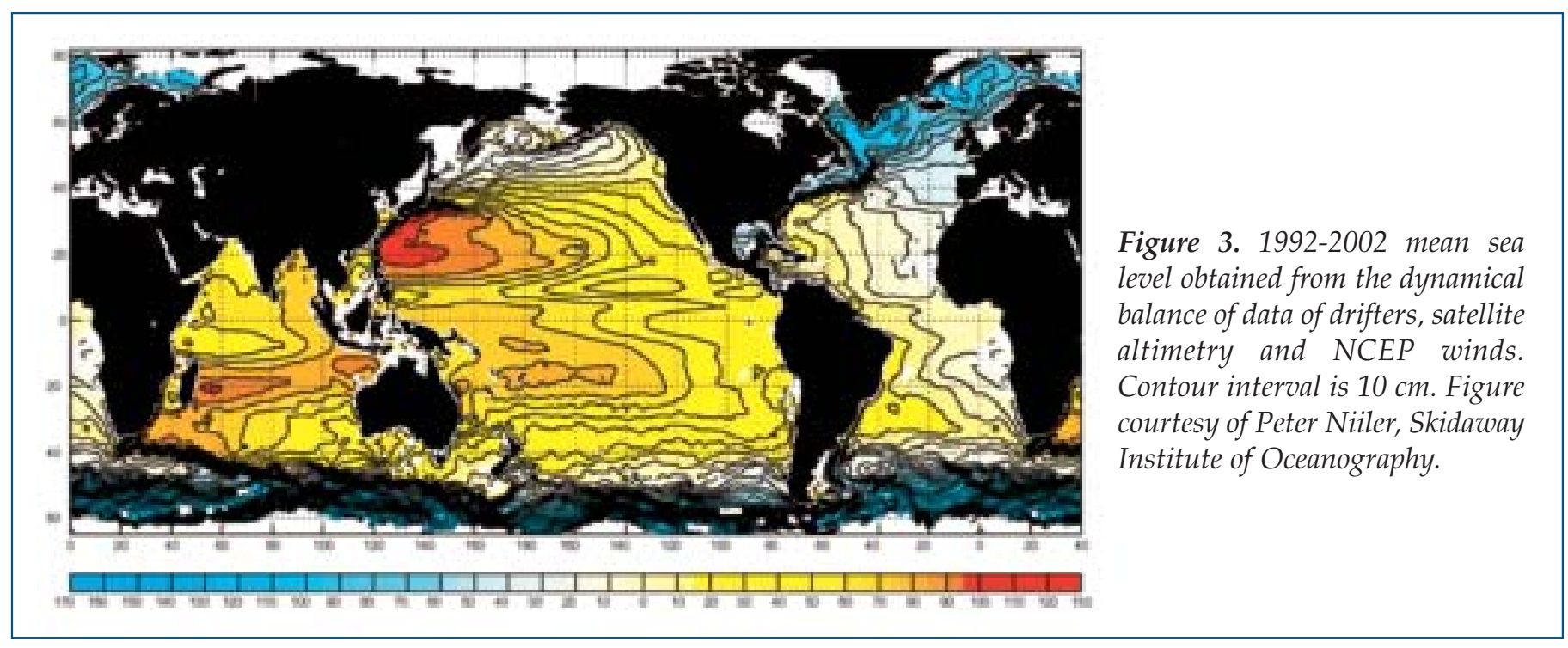

\begin{tabular}{|l|l|l|}
\hline \multicolumn{2}{|c}{ Technology developments needed by WOCE } \\
Observational method & 1982 Context & Development required \\
\hline Satellite altimetry & SeaSat 100 days in 1978 & New missions needed \\
\hline Scatterometer winds & SeaSat 100 days in 1978 & New missions needed \\
\hline Global Hydrography (T/S) & Very few sections recently occupied & $\begin{array}{l}\text { Greatly increased level of activity } \\
\text { (10,000 one time and 18,000 repeat stations) } \\
\text { Improved accuracy }\end{array}$ \\
\hline $\begin{array}{lll}\text { Global Hydrography } \\
\text { (tracers) }\end{array}$ & Last major effort GEOSECS & $\begin{array}{l}\text { Greatly increased scope } \\
\text { Bigger ships with longer endurance }\end{array}$ \\
\hline Subsurface floats & Only used on basin scale & New technique needed to track floats globally \\
\hline Drifters & Small numbers deployed & $\begin{array}{l}\text { More drifters } \\
\text { Less windage } \\
\text { Better lifetime }\end{array}$ \\
\hline XBTs & & $\begin{array}{l}\text { Expand sparse network } \\
\text { Add high density lines }\end{array}$ \\
\hline Shipboard ADCP & Prototype only & $\begin{array}{l}\text { Routine capability } \\
\text { Better navigation }\end{array}$ \\
\hline Sea level & & $\begin{array}{l}\text { Increase global coverage } \\
\text { Hourly data for altimeter calibration }\end{array}$ \\
\hline Air sea fluxes & $\begin{array}{l}\text { Improved ship board met data } \\
\text { Moored flux reference sites }\end{array}$ \\
\hline
\end{tabular}

Near-surface velocity fields measured by drifters were needed by both WOCE and TOGA and led to floats with longer lifetime, greatly enhanced performance in terms of their water-following ability and later to measurements of surface salinity, temperature and surprisingly atmospheric pressure from sensors capable of being submerged to depths of several metres. These drifters are now an essential element of the global observing system (Figure 3).
Other elements of WOCE's observing system required rather less innovation but called for planning and investment of resources on a hitherto unheard of scale. High quality, ship based CTD measurements $\left(\sim 0.001{ }^{\circ} \mathrm{C}\right.$ and 0.002 in salinity) were made routinely in the mid 1980s, but for the most part these were being carried out by a relatively small number of laboratories in regional experiments exploring the oceans' mesoscale variability. Such CTD measurements were a 


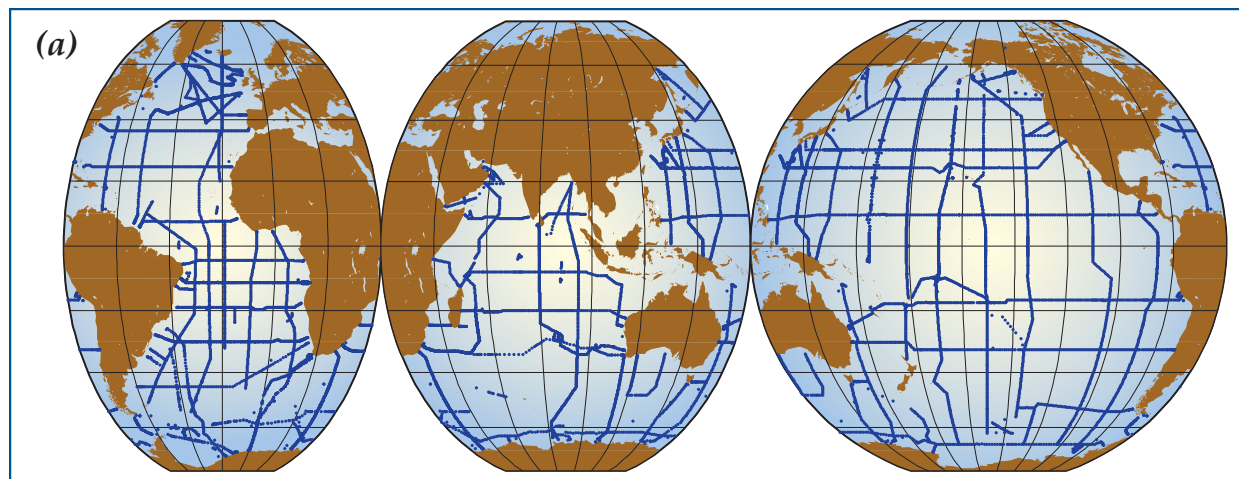

(b)

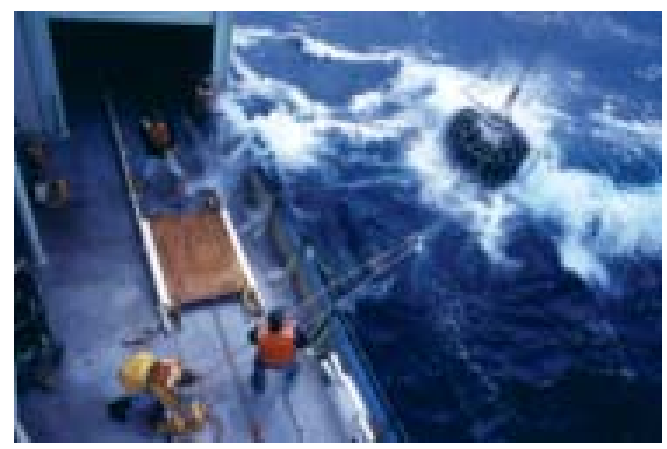

Figure 4. a) The global network of stations in the One-time WOCE Hydrographic Programme $(W H P) . \boldsymbol{b})$ Handling a large WOCE CTD package in rough weather. Figure courtesy of Woods Hole Oceanographic Institution.

observations extending over decades. These and several others will continue as ocean observatories linked to colocated measurements of airsea fluxes.

Just as TOGA demanded an innovative real-time data delivery system, so WOCE developed a data system capable of ensuring uniformity of data quality from laboratories scattered across 15 countries. The structure adopted was one of Data Assembly Centres each embedded in a laboratory with scientific expertise in one particular data stream and in the case of the WHP data, using independent Data Quality Experts to scrutinize observations.

The end product is a data set issued in its third and final version on 2 DVDs in November 2002 (approx 5 years after measurements ended) and containing the complete WOCE data set. It is also available online at http://www.nodc. noaa.gov/woce_v3/. It will be

central element of WOCE planning but were needed on a global network of trans-ocean sections in an effort sustained over 7 years (Figure 4). This CTD survey provided a vehicle by which the data set could be greatly enhanced by the collection of dissolved oxygen and nutrient data, by making measurements of naturally occurring and anthropogenic tracers (including chlorofluorocarbons and Tritium/Helium) and of the various elements of the oceanic $\mathrm{CO}_{2}$ system. Together these made up the WOCE Hydrographic Programme, (WHP). The WHP demanded large teams of scientists to work with cumbersome (up to $36 \times 10$ liter) CTD multisampler packages on repeated multi-week cruise legs (Figure 4). During one stage of WOCE planning the idea of a single dedicated vessel, dubbed " $\mathrm{R} / \mathrm{V}$ WOCE" was mooted but eventually dropped and instead existing ships (R/Vs Knorr and Melville in the USA and RRS Discovery in the UK) were lengthened and their capabilities enhanced.

Again the ambitious plan was completed and (in some respects) exceeded. The global $\mathrm{CO}_{2}$ survey was a collaboration between WOCE and the International Geosphere-Biosphere Program's Joint Global Ocean Flux Study (JGOFS). The data set, of unprecedented scope and quality, provides a 1990s baseline against which future (and past) changes in ocean properties can be determined.

A small number of sites notably near Bermuda and Hawaii now have time series of hydrographic followed in early 2004 by the publication of the first of four volumes of an atlas of WOCE hydrographic data.

Not all the developments in ocean observations were driven by WOCE and TOGA. Both programs benefitted greatly from the IT revolution of the 1980s and 90s. The benefit was not just from the increased computing power that permitted eddy-resolving global models to be run, but also from the development of the internet and the ready availability of e-mail. Indeed the planning of such international experiments would have been impossible without the ability to communicate electronically, and certainly the dissemination of data and information is now heavily dependent on the internet. The continuous availability of the Global Positioning System also meant that by the late 1990s positions of ships and instruments could be determined instantaneously to within $\sim 3$ meters and direction to a fraction of a degree making ship-board acoustic Doppler current profiler (ADCP) data of greater value and lowered ADCP measurements possible.

\section{Beyond WOCE and TOGA}

At the beginning of the $21^{\text {st }}$ century there is an increasing awareness of the need to monitor the changes that occur on earth so as to better understand the natural variability, to detect excursions from "normal" conditions and to be able to understand the causes and consequences of such excursions. These 
(a)

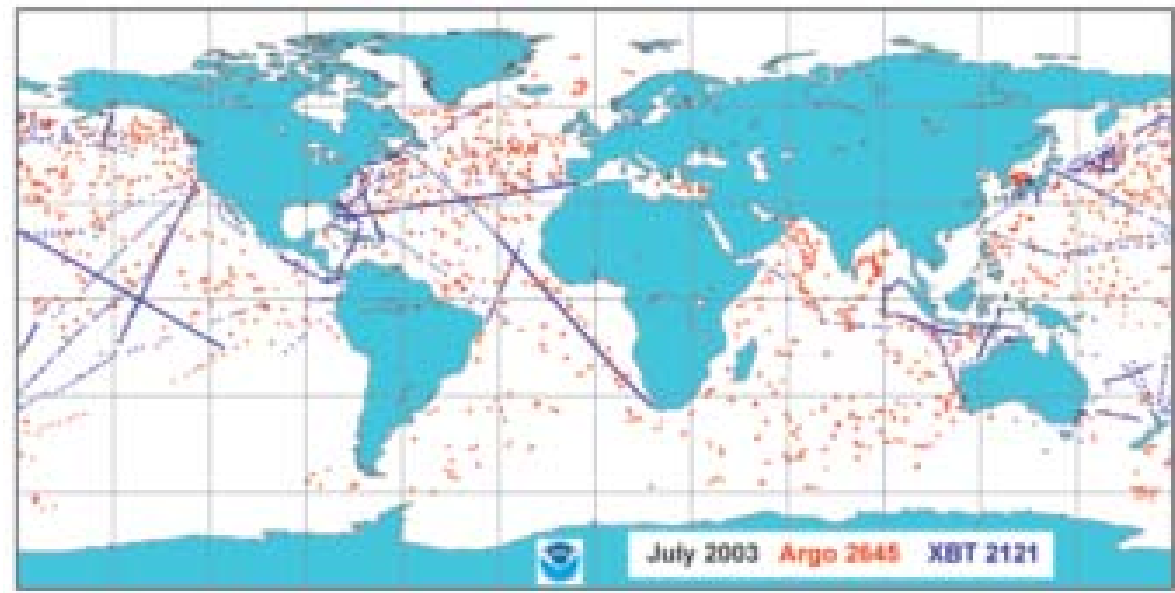

(b)

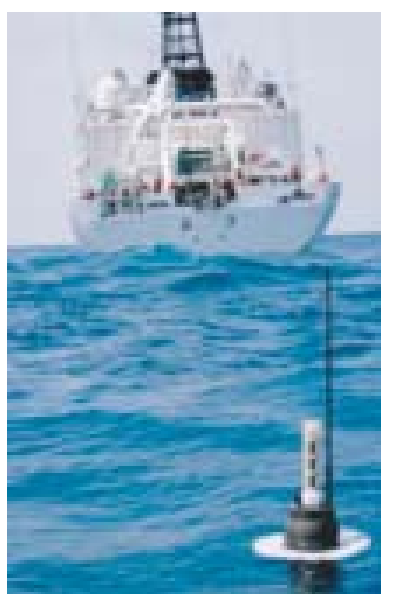

Figure 5. a) Positions from which data were delivered to users within 2 days during July 2003 from Argo floats (temperature and salinity to as deep as 2000m) and from high density Volunteer Observing Ship XBT lines (Temperature only to 750m). b) An Argo float just after launch from the Japanese Coast Guard Vessel Takuyo. Figure courtesy of Kensuke Takeuchi, JAMSTEC.

needs were reflected in the Earth Observations summit (http://www.earthobservationsummit.gov/) and in the earlier European initiative for Global Monitoring for Environmental Security (GMES) (http://www. gmes.info/what_is/index.html). The oceans are a vital element in this monitoring and thanks to the developments made by TOGA and WOCE most elements of the climate module of the Global Ocean Observing System (formally initiated in 1990 just as WOCE started its observational phase) are already in place (http://ioc.unesco.org/goos/). Those who planned WOCE and TOGA were visionaries and put their faith in the commitment of scientists and engineers to fulfill that vision. They have been amply rewarded and in consequence all of humankind may benefit.

Planning and implementing finite duration programs like TOGA and WOCE is however not the same as implementing monitoring systems that are expected to continue in perpetuity. In order to implement a sustained observing system new challenges must be overcome.

An example of these challenges can be seen in the Argo project, the outgrowth from the global array of WOCE subsurface floats. In the later stages of WOCE the ALACE was developed to measure temperature and salinity as each float surfaced to be positioned and download its data. Profiling floats are now being deployed to form a global network that will ultimately deliver 100,000 CTD profiles each year from the ice-free areas of the oceans deeper than $2 \mathrm{~km}$. This float array is made up of contributions both large and small from (at present) 16 national programs. Argo has already delivered a data set with relatively uniform distribution in space and time across entire basins that has never been available before. Figure 5 shows the distribution of Argo data for one month together with some of the high density (resolving ocean eddies) XBT lines that have continued since their establishment jointly by WOCE and TOGA.

\section{Challenges for Argo and Other Observing System Elements}

The challenges for Argo are technological, organizational and financial and are also representative of the challenges facing other elements of the ocean observing system, documented in the outcome of the OceanObs '99 conference (Koblinsky and Smith, 2001)

The technological challenges for Argo are:

- Build and deploy almost 1000 floats per year, each one being expected to work autonomously for 4 years at a unit cost presently of order $\$ 15,000$. Having multiple manufacturers in one sense provides security to the project but introduces the need to scrutinize the significance of subtle differences between the performance of each float type when constructing globally uniform data sets.

- Each float is made up from components from many suppliers-a change in any subcomponent introduces the potential for new float behavior or at worst a new float failure mode.

- Diagnosing the causes of float failure requires constant scrutiny by experts well versed in both float technology and ocean science. Rectification of a failure mode will often not be possible until several years after a batch of floats with a particular problem was deployed.

- As yet no salinity sensor has been devised that can be guaranteed to hold its calibration over a 4 year period. Thus, methods are being devised that allow sensor drift to be corrected. 
Comparisons with climatologies may however mask "real" and significant anomalies.

- Even when a program becomes "operational", continuing science input and technical development are needed on existing and on promising new methods, e.g. gliders and the development of autonomous biogeochemical sensors. From a climate standpoint much of this will come from the successor to TOGA and WOCE, the WCRP's Climate Variability and predictability project (CLIVAR, www.clivar.org). Introducing these technologies, when they are sufficiently mature, also presents a challenge of maintaining continuity and compatibility of observations.

There are organizational challenges

- Developing a data system capable of delivering the same data in two forms-real time after basic scrutiny and in delayed mode after comparison with climatological data and with other floats and data sources.

- Developing an effective partnership in each contributing country between the research community that has developed Argo to its present stage and operational agencies who would see it as their role to implement an ongoing programme.

- Striking an effective balance at an international level between the innovative flexibility of the academic research community and the more constrained but essential intergovernmental frameworks

For Argo, it will be a decade from the start of the project (2001) to the point where a multi-year data set from the full global array can be evaluated. That increases the challenge of securing the commitment of funds to implement the program (and its necessary infrastructure) in the long term. Overall there are resource commitments to a little less than half of the overall program.

Argo is closely linked to the Jason-1 altimeter satellite launched in 2001 and with the Global Ocean Data Assimilation Experiment (GODAE). Indeed all of the elements of the Global Ocean Observing System are mutually supportive and to some extent interdependent. Thus the development of effective data delivery systems for all data streams and improved data assimilation capabilities are essential.

\section{Back to the Future}

Argo and all the rest of the Global Ocean Observing System hold an exciting prospect for global ocean monitoring and for understanding our planet's climate. Such an era was envisioned in the pages of Oceanography in April 1989 when Henry Stommel presented a somewhat fanciful view of ocean monitoring using autonomous profilers. He wrote that piece at about the time that the prototype predecessor of the Argo float was being deployed. 15 years later one might contend that in many respects Stommel's vision has become reality.

And where then might we expect to be 15 years from now? Argo will be fully implemented and delivering its 100,000 CTD profiles per year from floats with a longer lifetime and greater reliability than the present generation. The float sensors will have better salinity stability and many floats will carry biogeochemical sensors. Most of the sections occupied during WOCE will have been reoccupied and, together with Argo data, will have revealed the patterns and magnitude of temperature and salinity changes and these will have been linked to changes in air-sea fluxes. We will have new inventories of ocean $\mathrm{CO}_{2}$. Arrays of moorings will monitor the ocean transports of heat in a few key locations and fleets of gliders will measure the transports and properties of boundary currents.

These measurements and many others will be assimilated into ocean models to give us predictions of the onset of future El Niño events and for any ocean region a daily "state of the ocean" showing the positions of major fronts will be available. And the remarkable thing is that, thanks to TOGA and WOCE, this is not as speculative as Stommel's vision but merely an extrapolation of today's capabilities. ed

\section{References}

Anderson, D.L.T., E.S. Sarachik, P.J. Webster and L.M. Rothstein, Eds., 1998: The TOGA Decade; Reviewing the Progress of El Niño Research and Prediction. J. Geophys, Res., 103, C7, 14167-14510.

Bernstein, R.L. (Ed.), 1982: SEASAT special issue I: Geophysical Evaluation. J. Geophys. Res., 87(C5) 3173-3438.

Canby, T.Y., 1984: El Nino's Ill Wind. National Geographic, February, 144-183.

Cane, M.A., 1983: Oceanographic events during El Niño. Science, 222, 1189-1195.

Crease, J., 1997: John Swallow, F.R.S., 1923-1994. Oceanography, 10(1), 27-28.

Davis, R.E., D.C. Webb, L.A. Regier and J. Dufour, 1992: The Autonomous, Lagrangian Circulation Explorer (ALACE) J. Atmos. Oceanic. Technol., 9, 264-285.

Kirwan, A.D., T.J. Ahrens and G.H. Born, 1983: SEASAT special issue II: Scientific Results. J. Geophys. Res., 88(C3), 1529-1952.

Koblinsky, C.J. and N.R. Smith, 2001: Observing the Oceans in the 21st Century. GODAE Project Office, Bureau of Meteorology, Melbourne, 604pp.

Roemmich D. and C. Wunsch, 1985: Two transatlantic meridional sections: meridional circulation and heat flux in the subtropical North Atlantic Ocean. Deep-Sea Res., 32, 619-664.

Siedler, G., J. Church and J. Gould, (Eds.) 2001: Ocean Circulation and Climate. Observing and modeling the global ocean. Vol 77, International Geophysics Series. Academic Press, 715pp.

Stommel, H., 1989: The Slocum Mission. Oceanography, 2(1), 22-25. 